\title{
Digital pathology-aided assessment of tumor-infiltrating $T$ lymphocytes in advanced stage, HPV-negative head and neck tumors
}

\author{
Emma J. de Ruiter ${ }^{1}$ D $\cdot$ Reinout H. de Roest ${ }^{2} \cdot$ Ruud H. Brakenhoff $^{2} \cdot$ C. René Leemans ${ }^{2} \cdot$ Remco de Bree $^{3}$. \\ Chris H. J. Terhaard ${ }^{4}$. Stefan M. Willems ${ }^{1}$
}

Received: 14 August 2019 / Accepted: 4 January 2020 / Published online: 24 January 2020

(c) The Author(s) 2020

\begin{abstract}
Aim This study aimed to evaluate the presence and prognostic value of tumor-infiltrating $\mathrm{T}$ cells in the tumor epithelium in advanced stage, HPV-negative head and neck squamous cell carcinoma (HNSCC) patients treated with primary chemoradiotherapy using digital pathology.

Methods Pre-treatment biopsies from 80 oropharyngeal, 52 hypopharyngeal, and 29 laryngeal cancer patients were collected in a tissue microarray (TMA) and immunohistochemically stained for T-cell markers CD3, CD4, CD8, FoxP3, and PD1, and for immune checkpoint PD-L1. For each marker, the number of positive tumor-infiltrating lymphocytes (TILs) per $\mathrm{mm}^{2}$ tumor epithelium was digitally quantified and correlated to overall survival (OS), disease-free survival (DFS), and locoregional control (LRC), as well as to clinicopathological characteristics. Differences in clinical outcome were estimated using Cox proportional hazard analysis and visualized using Kaplan-Meier curves.

Results The patient cohort had a 3-year OS of 58\%, with a median follow-up of 53 months. None of the T-cell markers showed a correlation with OS, DFS or LRC. A low $\mathrm{N}$ stage was correlated to a better prognosis (OS: HR 0.39, $p=0.0028$, DFS: HR 0.34, $p=<0.001$, LRC: HR 0.24, $p=0.008$ ). High TIL counts were more often observed in PD-L1-positive tumors $(p<0.05)$.

Conclusion This study showed an objective, digital pathology-aided method to assess TILs in the tumor epithelium. However, it did not provide evidence for a prognostic role of the presence of CD3 +, CD4+, CD8 +, FoxP3 +, and PD1 + TILs in the tumor epithelium of advanced stage, HPV-negative HNSCC patients treated with primary chemoradiotherapy.
\end{abstract}

Keywords Head and neck squamous cell carcinoma (HNSCC) · Tumor-infiltrating lymphocytes (TILs) · T cells · Prognostic biomarkers

Electronic supplementary material The online version of this article (https://doi.org/10.1007/s00262-020-02481-3) contains supplementary material, which is available to authorized users.

Emma J. de Ruiter

e.j.deruiter-2@umcutrecht.nl

1 Department of Pathology, University Medical Center Utrecht, Heidelberglaan 100, 3584 CX Utrecht,

The Netherlands

2 Department of Otolaryngology/Head and Neck Surgery, Cancer Center Amsterdam, Amsterdam University Medical Center, Amsterdam, The Netherlands

3 Department of Head and Neck Surgical Oncology, University Medical Center Utrecht, Utrecht, The Netherlands

4 Department of Radiotherapy, University Medical Center Utrecht, Utrecht, The Netherlands

\begin{tabular}{ll}
\multicolumn{2}{l}{ Abbreviations } \\
ACE-27 & Adult Comorbidity Evaluation-27 \\
AUC & Area under the curve \\
CI & Confidence interval \\
DFS & Disease-free survival \\
FFPE & Formalin fixed, paraffin embedded \\
HR & Hazard ratio \\
ICC & Intraclass correlation coefficient \\
LRC & Locoregional control \\
ROC & Receiver operating characteristics \\
TMA & Tissue microarray \\
UMC & University Medical Center \\
VUmc & Vrije Universiteit Medical Center
\end{tabular}




\section{Introduction}

Despite the improvement of treatment outcome with the use of radiotherapy in combination with concomitant chemotherapy, an estimated $25-50 \%$ of all head and neck squamous cell carcinoma (HNSCC) patients still face locoregional recurrence and overall survival remains poor [1]. Failure of locoregional control of HNSCC strongly contributes to morbidity and mortality [2, 3]. Identifying robust biomarkers predicting patients at risk for recurrent disease after therapy would be of great value in selecting the best treatment for each individual patient [4].

For many types of cancer, it has become clear that the interplay between tumor cells and their microenvironment strongly influences tumor aggressiveness and therapy resistance $[5,6]$. Therapies targeting the anti-tumor immune response are rapidly evolving and are already implemented in a variety of cancer types [7]. In HNSCC, immune checkpoint inhibitors nivolumab and pembrolizumab are recently incorporated in clinical practice, with other immunotherapeutic agents probably soon to follow [8].

Many studies indicated the presence of tumor-infiltrating lymphocytes (TILs) in the tumor microenvironment to be a prognostic factor for treatment outcome in different types of cancer [9]. Especially T cells have been studied extensively in this context [10-12]. In HNSCC, several studies showed a prognostic favorable role for several subtypes of tumorinfiltrating $\mathrm{T}$ cells [13]. Also in patient cohorts exclusively treated with primary radiotherapy with or without concomitant chemotherapy, the presence of $\mathrm{T}$ cells was correlated to a better treatment outcome. Especially high infiltration with CD3 + and CD8 + TILs appeared to be a prognostic favorable characteristic; the role of CD4 + and FoxP3 + TILs was less clear [14-17]. The CD8/FoxP3 ratio has also been suggested as a promising, potential biomarker [15, 18, 19]. However, as far as we know, this ratio has not been examined in this specific patient group before.

A limitation of many prognostic biomarker studies in HNSCC is the use of heterogeneous patient cohorts with respect to treatment modality, tumor stage, tumor subsite and HPV status and/or a small number of study subjects. Furthermore, consensus on robust cutoffs is lacking, because the method of assessing TILs varies strongly among studies [13].

In this study, we aimed to assess the presence and prognostic value of $\mathrm{CD} 3+, \mathrm{CD} 4+, \mathrm{CD} 8+, \mathrm{FoxP} 3+$, and PD1 + TILs, and the CD8/FoxP3 ratio in the tumor epithelium and its relation to prognosis. To do so, we used a relatively large patient cohort consisting of advanced stage, HPV-negative head and neck squamous cell carcinoma patients treated with chemoradiotherapy and an objective, digital pathology-aided scoring system.

\section{Materials and methods}

\section{Patients and clinical data}

This study was conducted using a consecutive, retrospective cohort of patients with HNSCC treated at the University Medical Center Utrecht (UMCU), Utrecht, and the Amsterdam UMC (location VUmc), between January 2009 and December 2014. Inclusion criteria were (1) stage III or IV, HPV-negative oropharyngeal, hypopharyngeal, and laryngeal squamous cell carcinoma, (2) treatment with radiotherapy with concomitant cisplatin or carboplatin with curative intent, and (3) availability of tumor tissue and clinical data on survival outcomes. Patients treated with surgical resection of the tumor, or having distant metastases, a medical history of radiotherapy in the head and neck area, or a prognosis-affecting double tumor or prior malignancy were excluded.

For each patient, the following clinical data were collected: age, sex, performance state, comorbidity, prior malignancies, tobacco and alcohol usage, tumor localization, tumor stage, $\mathrm{T}$ stage, $\mathrm{N}$ stage, total radiation dose, and total chemotherapy dose. Comorbidity was scored using the Adult Comorbidity Evaluation-27 (ACE-27) [20]. Performance state was scored using the WHO classification [21].

\section{Treatment protocol}

Standard treatment regimen existed of a total radiation dose of $70 \mathrm{~Gy}$ on the primary tumor and positive lymph nodes in 35 fraction of $2 \mathrm{~Gy}$, and a total dose of 46-57.75 Gy on the elective lymph nodes, in combination with cisplatin in a total dose of $300 \mathrm{mg} / \mathrm{m}^{2}$ body surface area in three divided doses every 3 weeks.

\section{Tissue microarray construction and immunohistochemistry}

From all included patients, formalin-fixed, paraffin-embedded (FFPE) pre-treatment biopsies were collected. Sections of the FFPE blocks were stained with hematoxylin and eosin (H\&E) and assessed by a dedicated head and neck pathologist (S.M. Willems) to mark representative tumor regions. For each patient, three $0.6 \mathrm{~mm}$ tissue cores were obtained from the assigned area of the FFPE blocks and collected in a tissue microarray (TMA). The TMA was constructed by a fully automated tissue microarray instrument, as described before [22].

TMA tissue sections $(4 \mu \mathrm{m})$ were immunohistochemically stained with antibodies for the following antigens: CD3 (A452; 1:200; DAKO), CD4 (SP35, 1:25; Cellmarque), CD8 (CD8/144B; 1:100; DAKO), FoxP3 (236A/E7; 1:750; 

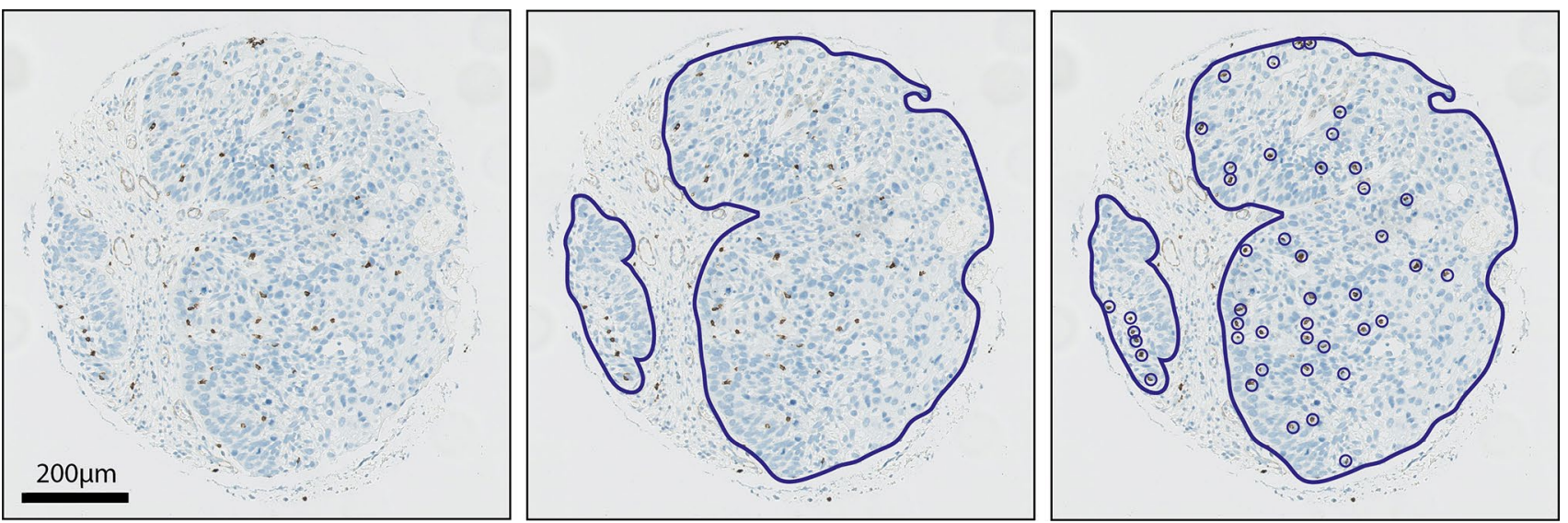

Fig. 1 Method of digital quantification of TILs. a Representative image of a TMA core. b For each TMA core, the tumor epithelium was annotated. $\mathbf{c}$ Positively stained TILs were quantified within the annotated area

Abcam), PD1 (NAT105; 1:100; Abcam), and PD-L1 (SP263, Ventana RTU). Staining was performed using a Ventana Bench Mark XT Autostainer (Ventana Medical Systems, Tucson, AZ, USA).

\section{HPV detection}

All cases included in this study were HPV-negative. Tumors were considered HPV-negative if less than $70 \%$ of tumor cells stained positive for $\mathrm{p} 16$ INK4a by immunohistochemistry (JC8, 1:1200, Immunologic). P16-positive tumors were tested for the presence of HPV-DNA by PCR and were excluded if high-risk HPV-DNA was detected [22, 23].

\section{Digital immunohistochemical analysis}

Stained sections of the TMA were digitalized using Aperio Scanscope XT slide scanner at a magnification of $40 \times$ resulting in a resolution of 0.233 microns per pixel. For each TMA core, the tumor epithelium was annotated and quantified using Imagescope 12.1 (Fig. 1). Within the annotated area, positively stained lymphocytes were counted. PD-L1 was scored positive if the mean percentage of stained tumor cells from the three TMA cores was more than 5\%; cells with any membranous staining were considered positive [24]. The immunohistochemical analysis was performed by a head and neck researcher (E. J. de Ruiter) and a dedicated head and neck pathologist (S. M. Willems), who were blinded for clinical outcome. Discrepancies were resolved by consensus. The two observers scored 50 TMA cores separately to calculate interobserver variability.

\section{Statistical analysis}

For each T-cell marker, the number of positive TILs per $\mathrm{mm}^{2}$ tumor epithelium was calculated by dividing the summed number of lymphocytes of the three corresponding TMA cores by the total tumor epithelium area of the three cores. Tumors were excluded from analysis if less than two TMA cores were assessable or if the total annotated tumor area was less than $0.1 \mathrm{~mm}^{2}$.

Intraclass correlation coefficients (ICC) between different TMA cores from the same patient were calculated using SPSS (SPSS statistics 23) based on a mean-rating $(k=3)$, absolute-agreement, two-way mixed-effects model (Koo 2016) [25].

The number of positive TILs $/ \mathrm{mm}^{2}$ was correlated to overall survival (OS), disease-free survival (DFS) and locoregional control (LRC). OS was defined as the number of days between the first day of treatment and the date of death, DFS as the number of days between the first day of treatment and the date of recurrence of disease or the date of death, and LRC as the number of days between the first day of treatment and the date of local or regional recurrence. Patients without an event were censored at the date of their last visit to the clinic.

Correlations between TIL counts and clinical variables were assessed by Mann-Whitney $U$ tests for dichotomous clinical variables, Kruskal-Wallis tests for clinical variables stratified in more than two groups, and Spearman correlation for continuous clinical variables. Correlations with OS, DFS, and LRC were assessed using Cox proportional hazards regression in $\mathrm{R}(\times 64$ 3.3.2) using the survival and survminer packages. To perform the regression analysis, TIL counts were $\log$ transformed by taking their $\log _{2}$. The predictive value of each T-cell marker was visualized by Kaplan-Meier curves comparing tumors with high and low 
TIL counts stratified by the median value; HRs and $p$-values accompanying the Kaplan-Meier curves were calculated using logrank tests.

\section{Results}

\section{Patient characteristics}

A total of 161 patients were eligible for inclusion, among which 80 were oropharyngeal, 52 hypopharyngeal, and 29 laryngeal cancer patients. The patient cohort had a 3-year OS of $58 \%$, with a median duration of follow-up of 53 months. Clinical characteristics of the patient cohort are summarized in Table 1.

Almost all patients were treated with radiotherapy in combination with cisplatin. Five patients were treated with carboplatin instead of cisplatin. 24 patients were initially treated with cisplatin, but switched to carboplatin due to adverse events. 19 patients discontinued treatment after two doses of cisplatin, receiving a total dose of $200 \mathrm{mg} / \mathrm{m}^{2}$ body surface area.

\section{Immunostaining of TILs on pre-treatment biopsies}

Figure 2a shows representative images of TMA cores containing low and high numbers of TILs. The distribution of the data is visualized in boxplot diagrams for each T-cell marker (Fig. 2b). Details on median values and ranges of TIL counts in TILs $/ \mathrm{mm}^{2}$ for each biomarker and median values and ranges of the $\log _{2}$-transformed TIL counts are shown in Supplementary Table 1.

Some tissue cores were lost during processing or did not contain any tumor epithelium. If less than two out of three TMA cores of one tumor were assessable or if the total annotated tumor area was less than $0.1 \mathrm{~mm}^{2}$, tumors were excluded from analysis of that specific marker.

Concordance between TMA cores from the same patients was good for $\mathrm{CD} 3$ (intraclass correlation coefficient (ICC): $0.86,95 \%$ confidence interval (CI) $0.80-0.90$ ), CD8 (ICC: 0.84, 95\% CI 0.78-0.89), FoxP3 (ICC: $0.80,95 \%$ CI $0.72-0.86$ ), and PD1 (ICC: $0.87,95 \%$ CI $0.81-0.91$ ) and moderate to good for CD4 (ICC: $0.69,95 \%$ CI $0.57-0.79$ ). Interobserver variability was generally very low (Supplementary Table 2).

\section{Correlation between TILs and clinicopathological characteristics}

PD-L1 positivity of the tumor was correlated to a high amount of CD3 $+(p=0.047), \mathrm{CD} 4+(p=0.021)$, CD $8+(p=0.038)$ and PD1 $+(p=0.014)$ TILs; Furthermore, a correlation was found between PD1 + TILs and
Table 1 Patient characteristics

\begin{tabular}{|c|c|c|c|}
\hline \multirow[t]{2}{*}{ Hospital } & VUmc & 97 & $(60.2 \%)$ \\
\hline & UMC Utrecht & 64 & $(39.8 \%)$ \\
\hline Age & Mean (SD) & 59.2 & (6.7) \\
\hline \multirow[t]{2}{*}{ Sex } & Male & 106 & $(65.8 \%)$ \\
\hline & Female & 55 & $(34.2 \%)$ \\
\hline \multirow[t]{4}{*}{ WHO } & 0 & 38 & $(23.6 \%)$ \\
\hline & 1 & 94 & $(58.4 \%)$ \\
\hline & 2 & 7 & $(4.3 \%)$ \\
\hline & Unknown & 22 & $(13.7 \%)$ \\
\hline \multirow[t]{4}{*}{ ACE-27 } & None (0) & 58 & $(36.0 \%)$ \\
\hline & Mild (1) & 78 & $(48.4 \%)$ \\
\hline & Moderate (2) & 24 & $(14.9 \%)$ \\
\hline & Severe (3) & 1 & $(0.6 \%)$ \\
\hline \multirow[t]{3}{*}{ Prior malignancy } & & 13 & $(8.1 \%)$ \\
\hline & HNSCC & 3 & $(1.9 \%)$ \\
\hline & Other & 10 & $(6.2 \%)$ \\
\hline \multirow[t]{4}{*}{ Tobacco usage } & Current & 120 & $(74.5 \%)$ \\
\hline & Former & 35 & $(21.7 \%)$ \\
\hline & Never & 5 & $(3.1 \%)$ \\
\hline & Unknown & 1 & $(0.6 \%)$ \\
\hline Packyears & Mean (SD) & 40.3 & (19.3) \\
\hline \multirow[t]{6}{*}{ Alcohol usage } & Current & 118 & $(73.3 \%)$ \\
\hline & 1-3/day & 51 & $(31.7 \%)$ \\
\hline & $\geq 4 /$ day & 67 & $(41.6 \%)$ \\
\hline & Former & 28 & $(17.4 \%)$ \\
\hline & Never & 14 & $(8.7 \%)$ \\
\hline & Unknown & 1 & $(0.6 \%)$ \\
\hline \multirow[t]{3}{*}{ Tumor location } & Oropharynx & 80 & $(59.7 \%)$ \\
\hline & Hypopharynx & 52 & $(32.3 \%)$ \\
\hline & Larynx & 29 & $(18.0 \%)$ \\
\hline \multirow[t]{5}{*}{ T stage } & $\mathrm{T} 1$ & 3 & $(1.9 \%)$ \\
\hline & $\mathrm{T} 2$ & 28 & $(17.4 \%)$ \\
\hline & $\mathrm{T} 3$ & 62 & $(38.5 \%)$ \\
\hline & $\mathrm{T} 4 \mathrm{a}$ & 52 & $(32.3 \%)$ \\
\hline & $\mathrm{T} 4 \mathrm{~b}$ & 16 & $(9.9 \%)$ \\
\hline \multirow[t]{7}{*}{$\mathrm{N}$ stage } & No & 24 & $(14.9 \%)$ \\
\hline & N1 & 21 & $(13.0 \%)$ \\
\hline & $\mathrm{N} 2 \mathrm{a}$ & 11 & $(6.8 \%)$ \\
\hline & $\mathrm{N} 2 \mathrm{~b}$ & 46 & $(28.6 \%)$ \\
\hline & $\mathrm{N} 2 \mathrm{c}$ & 53 & $(32.9 \%)$ \\
\hline & $\mathrm{N} 3$ & 5 & $(3.1 \%)$ \\
\hline & Unknown & 1 & $(0.6 \%)$ \\
\hline \multirow[t]{3}{*}{ Stage } & III & 28 & $(17.4 \%)$ \\
\hline & IVa & 121 & $(75.2 \%)$ \\
\hline & $\mathrm{IVb}$ & 20 & $(12.4 \%)$ \\
\hline \multirow[t]{3}{*}{ Chemotherapy completed } & Yes & 119 & $(73.9 \%)$ \\
\hline & Switch & 23 & $(14.3 \%)$ \\
\hline & No & 19 & $(11.8 \%)$ \\
\hline
\end{tabular}


Table 1 (continued)

\begin{tabular}{llll}
\hline Treatment outcome & No recurrence & 101 & $(62.7 \%)$ \\
Residu/recurrence & 60 & $(37.3 \%)$ \\
Locoregional & 40 & $(24.8 \%)$ \\
Distant & 30 & $(18.6 \%)$ \\
\hline
\end{tabular}

comorbidity. Patients with an ACE-27 score of none to mild were more likely to have a high PD1 + TIL count than patients with a score of moderate to severe $(p=0.012)$. All correlations between TILs and clinicopathological characteristics are shown in Supplementary Table 3.

\section{Correlation between TILs and treatment outcome}

The outcome of all survival analyses is shown in Table 2. No significant correlations were found between any of the TIL markers and OS, DFS, or LRC. Correlations between CD8 + TILs and treatment outcome were visualized in Kaplan-Meier curves (Fig. 3). Kaplan-Meier curves of the other biomarkers are shown in Supplementary Figs. 1-5.

Due to lack of correlation between TIL counts and survival data, no multivariate analysis was performed.

\section{Correlation between clinicopathological characteristics and treatment outcome}

The only clinical variable correlated to OS and DFS was $\mathrm{N}$ stage. N0 and N1 patients showed a significantly better OS (HR 0.39, 95\% CI 0.21-0.72, $p=0.0028$ ) and DFS (HR 0.34, $95 \%$ CI $0.19-0.62, p=<0.001)$ than $\mathrm{N} 2$ and N3 patients. $\mathrm{N}$ stage and WHO performance state were correlated to LRC. Patients with a low N stage had an increased LRC (HR 0.24, 95\% CI 0.086-0.69, $p=0.008)$, as did patients with a WHO performance score below 2 (HR 0.25, 95\% CI 0.075-0.81, $p=0.021)$.

\section{Discussion}

In this study, we assessed the presence and prognostic value of CD3, CD4, CD8, FoxP3, and PD1 positive TILs, as well as the CD8/FoxP3 ratio, in the head and neck tumor epithelium in pre-treatment biopsies of HNSCC patients using an objective, digital pathology-aided method.

In the last decades, it has become clear that the immune system plays an indispensable role in tumor development and progression [26]. It has therefore been a major target for the development of new treatment strategies, resulting in the implementation of various immunotherapeutic options in different types of cancer [27-29]. Also in HNSCC, the results of immunotherapy in recurrent and metastatic disease are promising $[8,30]$.

Previous studies have provided evidence that the presence of an immune response prior to treatment could enhance the effect of radiotherapy and chemotherapy [31-33], suggesting that the presence of TILs could be used as a predictive biomarker for treatment outcome. Indeed, in many types of cancer, the presence of immune cells in the tumor microenvironment was associated with a better treatment outcome [9].

The anti-tumor immune response is a complex process, involving various players of the innate and adaptive immune system [34, 35]. In this study, we examined the role of the T cell, the most studied subtype as it is able to directly target tumor cells. However, different subsets of $\mathrm{T}$ cells with different functions exist. We assessed TILs expressing CD3, CD4, CD8, FoxP3 and PD1.

First, a correlation was observed between infiltration of TILs and PD-L1 expression in the tumor: PD-L1-positive tumors showed higher $\mathrm{CD} 3+, \mathrm{CD} 4+, \mathrm{CD} 8+$ and PD1 + TIL counts in the tumor epithelium than PD-L1-negative tumors, a phenomenon that was observed before in HNSCC and in other types of cancer [36-38]. It is an important observation that PD-L1 expression is more often observed in highly infiltrated head and neck tumors, because it suggests that these tumors might be likely to benefit from immunotherapy targeting the PD1/PD-L1 interaction [39].

Second, we assessed the prognostic value of $\mathrm{CD} 3+$, $\mathrm{CD} 4+, \mathrm{CD} 8+$, FoxP3 +, and PD1 + TILs in HNSCC. Several studies showed a prognostic favorable role for the presence of $\mathrm{T}$ cells. However, the literature on the prognostic role of TILs in HNSCC assessed by immunohistochemistry predominantly comprised small studies, using heterogeneous patient cohorts, providing insufficient data to draw robust conclusions on subgroups [13]. Methods differ strongly among studies and are not always clearly described, hindering consensus on cutoff values and implementation of TILs as predictive biomarkers in clinical practice. Furthermore, studies using TCGA datasets showed a prognostic favorable effect of immune cell profiles in HNSCC as well [40], but RNA-sequencing data do not tell in which compartment of the tumor the immune cells are located, while the prognostic effect of TILs in the tumor epithelium might differ from the effect of TILs in the tumor stroma [41].

In this study, we used a relatively large patient cohort, with a high homogeneity regarding treatment modality, tumor stage, and HPV status, in which we assessed the presence of $\mathrm{T}$ cells in the tumor epithelium using an objective method. Given all technical and clinical optimizations in our study design, we did not find a prognostic role for T-cell markers CD3, CD4, CD8, FoxP3, PD1 and the CD8/FoxP3 ratio in the head and neck tumor epithelium, an observation that is in contrast with previous studies [13]. 
a
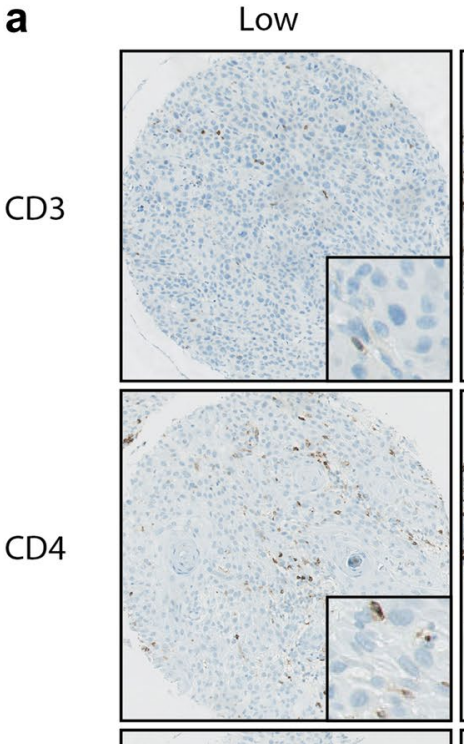

CD8

CD8
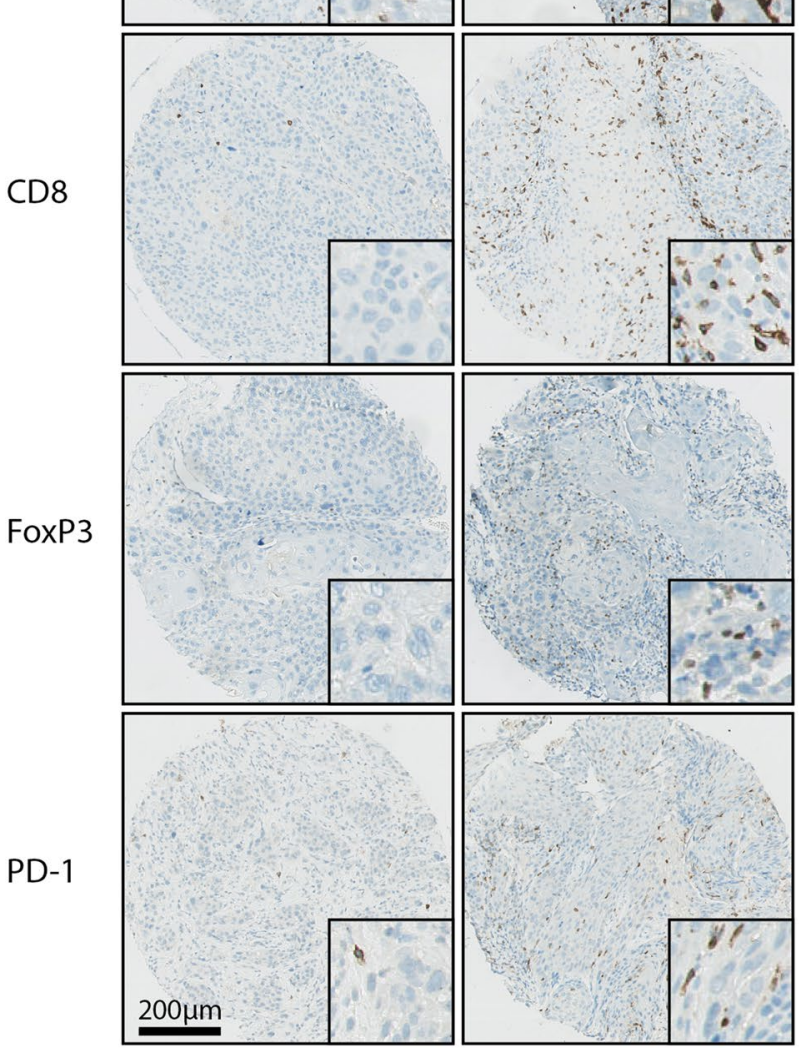

b

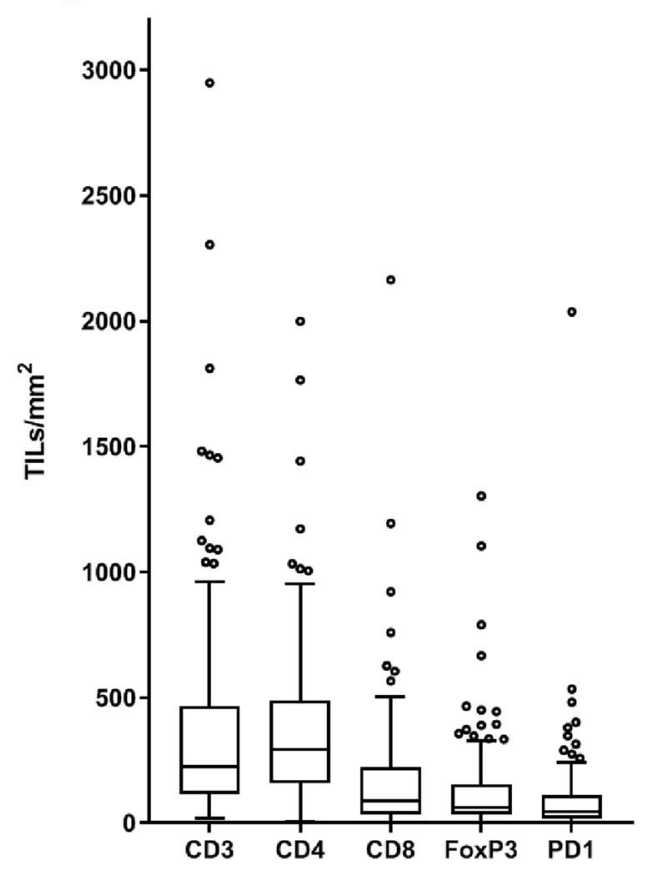

Fig. 2 Variability of number of TIL subsets. a Representative images of TMA cores containing low and high numbers of CD3+, CD4+, $\mathrm{CD} 8+$, FoxP3 + and PD1 + TILs. b Boxplot diagrams of the number of TILs/mm² tumor epithelium

A possible explanation for these findings may lie in the specificity of our patient cohort regarding treatment modality and HPV status. All patients in the study cohort were diagnosed with advanced stage HNSCC and were exclusively treated with chemoradiotherapy, while most studies assessing the prognostic value of $\mathrm{T}$ cells also included surgically treated patients [42-49]. It was shown that (chemo) radiotherapy affects the tumor microenvironment and is able to enhance the anti-tumor immune response in rectal and pancreatic cancer [50-54]. This could mean that the pre-treatment composition of the tumor microenvironment is of less importance than the anti-tumor immune response induced by the (chemo)radiotherapy. However, this is not supported by multiple studies that do show an association between the pre-treatment presence of TILs and treatment outcome $[14,55,56]$. 
Table 2 Univariate analysis of the correlation between biomarkers and OS, DFS and LRC

\begin{tabular}{|c|c|c|c|c|c|}
\hline Marker & Comparison & No of cases & HR & $95 \% \mathrm{CI}$ & $p$ value \\
\hline \multicolumn{6}{|l|}{ Overall survival } \\
\hline CD3 & Per 1 increase $\left(\log _{2}\right)$ & 152 & 0.95 & $(0.82-1.11)$ & 0.53 \\
\hline CD4 & Per 1 increase $\left(\log _{2}\right)$ & 149 & 0.96 & $(0.80-1.16)$ & 0.68 \\
\hline CD8 & Per 1 increase $\left(\log _{2}\right)$ & 150 & 0.95 & $(0.84-1.07)$ & 0.40 \\
\hline FoxP3 & Per 1 increase $\left(\log _{2}\right)$ & 154 & 0.96 & $(0.83-1.12)$ & 0.59 \\
\hline PD1 & Per 1 increase $\left(\log _{2}\right)$ & 141 & 0.92 & $(0.81-1.04)$ & 0.17 \\
\hline CD8FoxP3ratio & Per 1 increase $\left(\log _{2}\right)$ & 146 & 0.98 & $(0.84-1.13)$ & 0.76 \\
\hline PD-L1 & $<5 \%$ vs $\geq 5 \%$ & 158 & 1.27 & $(0.75-2.14)$ & 0.38 \\
\hline \multirow[t]{3}{*}{ Tumor location } & Larynx & 161 & Ref. & & \\
\hline & Oropharynx & & 1.94 & $(0.94-4.00)$ & 0.074 \\
\hline & Hypopharynx & & 1.40 & $(0.64-3.04)$ & 0.40 \\
\hline T stage & T1-3 vs T4 & 161 & 0.79 & $(0.50-1.26)$ & 0.33 \\
\hline $\mathrm{N}$ stage & N0-1 vs N2-3 & 161 & 0.39 & $(0.21-0.72)$ & 0.0028 \\
\hline Age & Per year increase & 161 & 1.00 & $(0.96-1.03)$ & 0.89 \\
\hline Sex & Male vs Female & 161 & 1.21 & $(0.73-2.00)$ & 0.46 \\
\hline ACE-27 & $<2$ vs $\geq 2$ & 161 & 0.75 & $(0.40-1.39)$ & 0.35 \\
\hline WHO & $<2 \mathrm{vs} \geq 2$ & 149 & 0.65 & $(0.36-1.18)$ & 0.15 \\
\hline \multicolumn{6}{|c|}{ Disease-free survival } \\
\hline CD3 & Per 1 increase $\left(\log _{2}\right)$ & 152 & 0.95 & $(0.82-1.10)$ & 0.49 \\
\hline $\mathrm{CD} 4$ & Per 1 increase $\left(\log _{2}\right)$ & 149 & 0.97 & $(0.81-1.15)$ & 0.72 \\
\hline CD8 & Per 1 increase $\left(\log _{2}\right)$ & 150 & 0.94 & $(0.84-1.04)$ & 0.23 \\
\hline FoxP3 & Per 1 increase $\left(\log _{2}\right)$ & 154 & 0.99 & $(0.86-1.13)$ & 0.84 \\
\hline PD1 & Per 1 increase $\left(\log _{2}\right)$ & 141 & 0.91 & $(0.81-1.03)$ & 0.12 \\
\hline CD8FoxP3ratio & Per 1 increase $\left(\log _{2}\right)$ & 146 & 0.92 & $(0.80-1.06)$ & 0.24 \\
\hline PD-L1 & $<5 \%$ vs $\geq 5 \%$ & 158 & 1.34 & $(0.82-2.20)$ & 0.25 \\
\hline \multirow[t]{3}{*}{ Tumor location } & Larynx & 161 & ref & & \\
\hline & Oropharynx & & 1.50 & $(0.79-2.85)$ & 0.21 \\
\hline & Hypopharynx & & 1.21 & $(0.61-2.39)$ & 0.59 \\
\hline T stage & $\mathrm{T} 1-3$ vs $\mathrm{T} 4$ & 161 & 0.93 & $(0.60-1.44)$ & 0.73 \\
\hline $\mathrm{N}$ stage & N0-1 vs N2-3 & 161 & 0.34 & $(0.19-0.62)$ & $<0.001$ \\
\hline Age & Per year increase & 161 & 1.00 & $(0.97-1.03)$ & 0.84 \\
\hline Sex & Male vs Female & 161 & 1.18 & $(0.74-1.88)$ & 0.49 \\
\hline ACE-27 & $<2 \mathrm{vs} \geq 2$ & 161 & 0.89 & $(0.49-1.61)$ & 0.70 \\
\hline WHO & $<2 \mathrm{vs} \geq 2$ & 149 & 0.69 & $(0.40-1.20)$ & 0.17 \\
\hline \multicolumn{6}{|c|}{ Locoregional control } \\
\hline CD3 & Per 1 increase $\left(\log _{2}\right)$ & 152 & 1.03 & $(0.83-1.28)$ & 0.77 \\
\hline CD4 & Per 1 increase $\left(\log _{2}\right)$ & 149 & 1.02 & $(0.77-1.33)$ & 0.92 \\
\hline CD8 & Per 1 increase $\left(\log _{2}\right)$ & 150 & 1.01 & $(0.85-1.19)$ & 0.92 \\
\hline FoxP3 & Per 1 increase $\left(\log _{2}\right)$ & 154 & 1.14 & $(0.92-1.40)$ & 0.23 \\
\hline PD1 & Per 1 increase $\left(\log _{2}\right)$ & 141 & 0.96 & $(0.80-1.14)$ & 0.62 \\
\hline CD8FoxP3ratio & Per 1 increase $\left(\log _{2}\right)$ & 146 & 0.92 & $(0.75-1.13)$ & 0.43 \\
\hline PD-L1 & $<5 \%$ vs $\geq 5 \%$ & 158 & 1.71 & $(0.78-3.72)$ & 0.18 \\
\hline \multirow[t]{3}{*}{ Tumor location } & Larynx & 161 & ref & & \\
\hline & Oropharynx & & 2.23 & $(0.77-6.47)$ & 0.14 \\
\hline & Hypopharynx & & 1.70 & $(0.55-5.26)$ & 0.36 \\
\hline $\mathrm{T}$ stage & $\mathrm{T} 1-3$ vs $\mathrm{T} 4$ & 161 & 0.85 & $(0.45-1.60)$ & 0.61 \\
\hline $\mathrm{N}$ stage & N0-1 vs N2-3 & 161 & 0.24 & $(0.086-0.69)$ & 0.008 \\
\hline Age & Per year increase & 161 & 1.01 & $(0.96-1.06)$ & 0.61 \\
\hline Sex & Male vs female & 161 & 1.17 & $(0.59-2.32)$ & 0.66 \\
\hline ACE-27 & $<2 \mathrm{vs} \geq 2$ & 161 & 1.17 & $(0.46-3.00)$ & 0.75 \\
\hline WHO & $<2 \mathrm{vs} \geq 2$ & 149 & 0.25 & $(0.075-0.81)$ & 0.021 \\
\hline
\end{tabular}

The correlation between biomarkers and OS, DFS, and LRC was assessed in a Cox proportional hazards regression. TIL counts and CD8/FoxP3 ratio were log transformed prior to the regression. The prognostic value of biomarkers is expressed as hazard ratios (HR), 95\% confidence intervals (95\% CI) and $p$ values. None of the T-cell markers showed a significant association with OS, DFS, or LRC. Patients with an N 
Table 2 (continued)

stage $\leq 1$ showed a better OS, DFS and LRC than patients with an $\mathrm{N}$ stage of $\geq 2$. A lower WHO performance state was correlated to a better LRC

Statistically significant $p$-values (values below 0.05 ) are denoted in bold

Fig. 3 Association between the number of CD8 + TILs and clinical outcome. Kaplan-Meier curves visualizing the association between the number of CD8 + TILs in the tumor epithelium and OS (a), DFS (b), and LRC (c). The median number of CD8 + TILs was used as cutoff for the survival analysis. No association was found between the number of CD8 + TILs and OS, DFS, or LRC

Also, we exclusively included patients with HPV-negative head and neck tumors. According to several studies, a more prominent immune response is observed in HPV-positive tumors compared to HPV-negative tumors, and some studies suggested that TILs play a more important role in HPVpositive tumors than in HPV-negative tumors [15, 48, 57, 58], which might explain the lack of prognostic value of T-cell markers in our patient cohort. However, there are also studies that suggest the opposite [14, 59].

Another important remark in the light of our results is the fact that we specifically assessed T cells in the tumor epithelium. Stromal T cells have been shown to have their effect on prognosis and treatment outcome as well and it was suggested that the prognostic significance of intra-epithelial and stromal TILs differs [41]. It might be possible that the prognostic value of $\mathrm{T}$ cells in the tumor microenvironment is completely explained by their presence in the tumor stroma. This was also suggested by Oguejiofor et al., who used a similar patient cohort [17]. However, in our study, a tissue microarray was used for staining and quantifying TILs and the amount of tumor stroma varied strongly among the different cores. Therefore, assessing TILs in the tumor stroma was not attempted.

Lastly, this study used TMAs, which only comprise a part of the tumor biopsy and might not adequately represent the original tumor. However, three cores were taken per patient, which should take account of heterogeneity within the tumor biopsy [60]. A bigger restraint might be the fact that the researchers were limited in the usage of patient material in the first place. As the primary treatment was chemoradiotherapy and not surgery, only small pre-treatment biopsies from the periphery of the tumor were available for research. Immune cell infiltration has been shown to differ between different parts of the tumor, which might explain the discrepancy we found with studies that assessed complete resected tumor lumps. However, it is inherent to the organ-sparing nature of primary chemoradiotherapy that only a small part of the tumor tissue is available for examination, which not only limits research, but has to be taken into consideration in diagnostics as well.
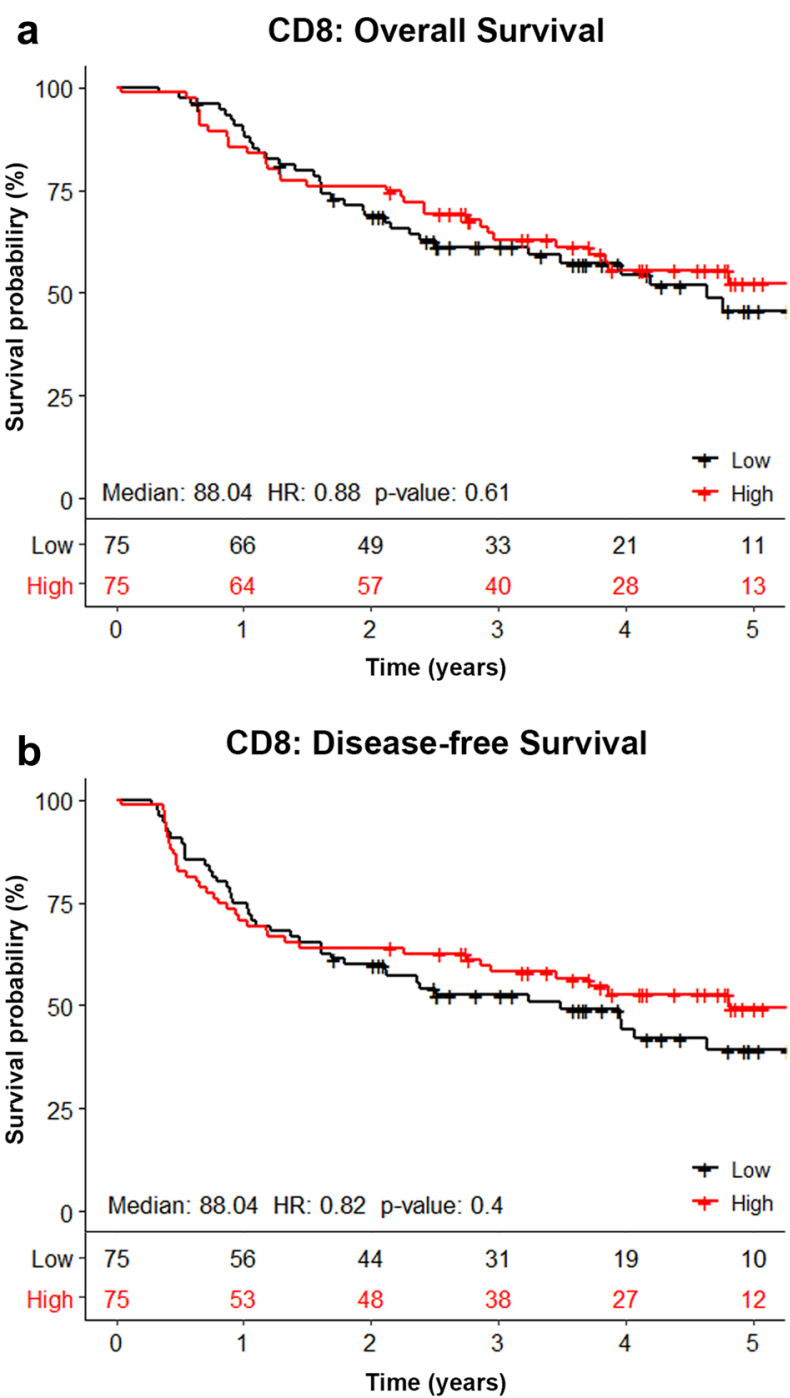

C

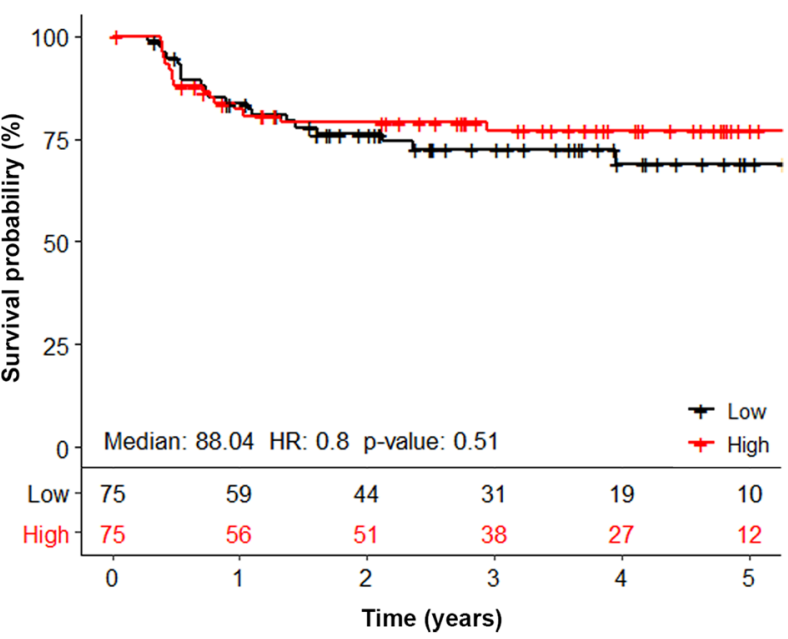


In conclusion, this study did not provide evidence for a prognostic value of the presence of $\mathrm{CD} 3+, \mathrm{CD} 4+, \mathrm{CD} 8+$, FoxP3 + , and PD1 + T lymphocytes in the tumor epithelium of advanced stage, HPV-negative HNSCC patients treated with primary chemoradiotherapy. However, an objective method to assess TILs in the tumor epithelium was described.

Acknowledgements The authors would like to thank Domenico Castigliego, Jojanneke Renes, and Petra van der Weide for their help with tissue collection and immunohistochemical staining, Michaël Frank for counsel about statistical analysis, and prof. Dr. E. Bloemena for providing tumor samples from the Amsterdam UMC.

Author contributions EJDR and SMW designed, performed and analyzed the research. RHDR, RHB and CRL contributed to collecting tumor specimens and clinical data from patients treated in the Amsterdam UMC, location VUmc. Remco de Bree and CHJT contributed to the collection of clinical data from patients treated in the UMC Utrecht. EJDR and SMW wrote the manuscript.

Funding This study was supported by the Dutch Cancer Society (Project Numbers: A6C 7072 and 10764).

\section{Compliance with ethical standards}

Conflict of interest The authors declare that they have no conflicts of interest.

Ethical approval and ethical standards. The use of anonymous archival leftover material from patients treated in the UMC Utrecht and in the Amsterdam University Medical Center was approved by the Biobank Research Ethics Committee of the UMC Utrecht (Protocol Number 18-233).

Informed consent For this study, only anonymous archival leftover pathology material was used. Therefore, no informed consent is required according to Dutch legislation (www.fedora.org), as this use of redundant tissue for research purposes is part of the standard treatment agreement with patients in hospitals in The Netherlands [61].

Open Access This article is licensed under a Creative Commons Attribution 4.0 International License, which permits use, sharing, adaptation, distribution and reproduction in any medium or format, as long as you give appropriate credit to the original author(s) and the source, provide a link to the Creative Commons licence, and indicate if changes were made. The images or other third party material in this article are included in the article's Creative Commons licence, unless indicated otherwise in a credit line to the material. If material is not included in the article's Creative Commons licence and your intended use is not permitted by statutory regulation or exceeds the permitted use, you will need to obtain permission directly from the copyright holder. To view a copy of this licence, visit http://creativecommons.org/licenses/by/4.0/.

\section{References}

1. Argiris A, Karamouzis MV, Raben D, Ferris RL (2008) Head and neck cancer. Lancet 371(9625):1695-1709. https://doi. org/10.1016/S0140-6736(08)60728-X
2. Ho AS, Kraus DH, Ganly I, Lee NY, Shah JP, Morris LG (2014) Decision making in the management of recurrent head and neck cancer. Head Neck 36(1):144-151. https://doi.org/10.1002/ hed. 23227

3. Agra IM, Filho JG, Martins EP, Kowalski LP (2010) Second salvage surgery for re-recurrent oral cavity and oropharynx carcinoma. Head Neck 32(8):997-1002. https://doi.org/10.1002/ hed. 21298

4. Begg AC (2012) Predicting recurrence after radiotherapy in head and neck cancer. Semin Radiat Oncol 22(2):108-118. https://doi. org/10.1016/j.semradonc.2011.12.002

5. Hadrup S, Donia M, Thor Straten P (2013) Effector CD4 and CD8 T cells and their role in the tumor microenvironment. Cancer Microenviron 6(2):123-133. https://doi.org/10.1007/s1230 7-012-0127-6

6. Curry JM, Sprandio J, Cognetti D, Luginbuhl A, Bar-ad V, Pribitkin E, Tuluc M (2014) Tumor microenvironment in head and neck squamous cell carcinoma. Semin Oncol 41(2):217-234. https:// doi.org/10.1053/j.seminoncol.2014.03.003

7. Zhang H, Chen J (2018) Current status and future directions of cancer immunotherapy. J Cancer 9(10):1773-1781. https://doi. org $/ 10.7150 /$ jca. 24577

8. Moskovitz JM, Moy J, Seiwert TY, Ferris RL (2017) Immunotherapy for head and neck squamous cell carcinoma: a review of current and emerging therapeutic options. Oncologist 22(6):680-693. https://doi.org/10.1634/theoncologist.2016-0318

9. Gooden MJ, de Bock GH, Leffers N, Daemen T, Nijman HW (2011) The prognostic influence of tumour-infiltrating lymphocytes in cancer: a systematic review with meta-analysis. Br J Cancer 105(1):93-103. https://doi.org/10.1038/bjc.2011.189

10. Knocke S, Fleischmann-Mundt B, Saborowski M, Manns MP, Kuhnel F, Wirth TC, Woller N (2016) Tailored tumor immunogenicity reveals regulation of CD4 and CD8 T Cell responses against cancer. Cell Rep 17(9):2234-2246. https://doi. org/10.1016/j.celrep.2016.10.086

11. McIntire PJ, Irshaid L, Liu Y, Chen Z, Menken F, Nowak E, Shin SJ, Ginter PS (2018) Hot spot and whole-tumor enumeration of CD8(+) tumor-infiltrating lymphocytes utilizing digital image analysis is prognostic in triple-negative breast cancer. Clin Breast Cancer 18(6):451-458 e451. https://doi.org/10.1016/j. clbc.2018.04.019

12. McIntire PJ, Zhong E, Patel A, Khani F, D'Alfonso T, Chen Z, Shin SJ, Ginter PS (2018) Hotspot enumeration of CD8+ tumor infiltrating lymphocyte using digital image analysis in triple negative breast Cancer yields consistent results. Hum Pathol. https:// doi.org/10.1016/j.humpath.2018.10.014

13. de Ruiter EJ, Ooft ML, Devriese LA, Willems SM (2017) The prognostic role of tumor infiltrating T-lymphocytes in squamous cell carcinoma of the head and neck: a systematic review and meta-analysis. Oncoimmunology 6(11):e1356148. https://doi. org/10.1080/2162402X.2017.1356148

14. Balermpas P, Michel Y, Wagenblast J, Seitz O, Weiss C, Rodel F, Rodel C, Fokas E (2014) Tumour-infiltrating lymphocytes predict response to definitive chemoradiotherapy in head and neck cancer. Br J Cancer 110(2):501-509. https://doi.org/10.1038/bjc.2013.640

15. Nasman A, Romanitan M, Nordfors C, Grun N, Johansson H, Hammarstedt L, Marklund L, Munck-Wikland E, Dalianis T, Ramqvist T (2012) Tumor infiltrating CD8+ and Foxp3+ lymphocytes correlate to clinical outcome and human papillomavirus (HPV) status in tonsillar cancer. PLoS ONE 7(6):e38711. https:// doi.org/10.1371/journal.pone.0038711

16. Nordfors C, Grun N, Tertipis N, Ahrlund-Richter A, Haeggblom L, Sivars L, Du J, Nyberg T, Marklund L, Munck-Wikland E, Nasman A, Ramqvist T, Dalianis T (2013) CD8+ and CD4+ tumour infiltrating lymphocytes in relation to human papillomavirus status and clinical outcome in tonsillar and base of tongue 
squamous cell carcinoma. Eur J Cancer 49(11):2522-2530. https ://doi.org/10.1016/j.ejca.2013.03.019

17. Oguejiofor K, Hall J, Slater C, Betts G, Hall G, Slevin N, Dovedi S, Stern PL, West CM (2015) Stromal infiltration of CD8 T cells is associated with improved clinical outcome in HPV-positive oropharyngeal squamous carcinoma. Br J Cancer 113(6):886-893. https://doi.org/10.1038/bjc.2015.277

18. Baras AS, Drake C, Liu JJ, Gandhi N, Kates M, Hoque MO, Meeker A, Hahn N, Taube JM, Schoenberg MP, Netto G, Bivalacqua TJ (2016) The ratio of CD8 to Treg tumor-infiltrating lymphocytes is associated with response to cisplatin-based neoadjuvant chemotherapy in patients with muscle invasive urothelial carcinoma of the bladder. Oncoimmunology 5(5):e1134412. https ://doi.org/10.1080/2162402X.2015.1134412

19. Suzuki H, Chikazawa N, Tasaka T, Wada J, Yamasaki A, Kitaura Y, Sozaki M, Tanaka M, Onishi H, Morisaki T, Katano M (2010) Intratumoral CD8(+) T/FOXP3 (+) cell ratio is a predictive marker for survival in patients with colorectal cancer. Cancer Immunol Immunother 59(5):653-661. https://doi.org/10.1007/ s00262-009-0781-9

20. Piccirillo JF (1995) Inclusion of comorbidity in a staging system for head and neck cancer. Oncology (Will Park) 9(9):831-836 (discussion 841, 845-838)

21. Oken MM, Creech RH, Tormey DC, Horton J, Davis TE, McFadden ET, Carbone PP (1982) Toxicity and response criteria of the Eastern Cooperative Oncology Group. Am J Clin Oncol 5(6):649-655

22. van Kempen PM, van Bockel L, Braunius WW, Moelans CB, van Olst M, de Jong R, Stegeman I, van Diest PJ, Grolman W, Willems SM (2014) HPV-positive oropharyngeal squamous cell carcinoma is associated with TIMP3 and CADM1 promoter hypermethylation. Cancer Med 3(5):1185-1196. https://doi.org/10.1002/ cam4.313

23. Smeets SJ, Hesselink AT, Speel EJ, Haesevoets A, Snijders PJ, Pawlita M, Meijer CJ, Braakhuis BJ, Leemans CR, Brakenhoff RH (2007) A novel algorithm for reliable detection of human papillomavirus in paraffin embedded head and neck cancer specimen. Int J Cancer 121(11):2465-2472. https://doi.org/10.1002/ijc.22980

24. Ferris RL, Blumenschein G Jr, Fayette J, Guigay J, Colevas AD, Licitra L, Harrington K, Kasper S, Vokes EE, Even C, Worden F, Saba NF, Iglesias Docampo LC, Haddad R, Rordorf T, Kiyota N, Tahara M, Monga M, Lynch M, Geese WJ, Kopit J, Shaw JW, Gillison ML (2016) Nivolumab for recurrent squamous-cell carcinoma of the head and neck. N Engl J Med 375(19):1856-1867. https://doi.org/10.1056/NEJMoa1602252

25. Koo TK, Li MY (2016) A guideline of selecting and reporting intraclass correlation coefficients for reliability research. J Chiropr Med 15(2):155-163. https://doi.org/10.1016/j.jcm.2016.02.012

26. Hanahan D, Weinberg RA (2011) Hallmarks of cancer: the next generation. Cell 144(5):646-674. https://doi.org/10.1016/j. cell.2011.02.013

27. Kalyan A, Kircher S, Shah H, Mulcahy M, Benson A (2018) Updates on immunotherapy for colorectal cancer. J Gastrointest Oncol 9(1):160-169. https://doi.org/10.21037/jgo.2018.01.17

28. Tsiara A, Liontos M, Kaparelou M, Zakopoulou R, Bamias A, Dimopoulos MA (2018) Implementation of immunotherapy in the treatment of advanced non-small cell lung cancer (NSCLC). Ann Transl Med 6(8):144. https://doi.org/10.21037/atm.2018.02.07

29. Vonderheide RH, Domchek SM, Clark AS (2017) Immunotherapy for breast cancer: what are we missing? Clin Cancer Res 23(11):2640-2646. https://doi.org/10.1158/1078-0432. CCR-16-2569

30. Ling DC, Bakkenist CJ, Ferris RL, Clump DA (2018) Role of immunotherapy in head and neck cancer. Semin Radiat Oncol 28(1):12-16. https://doi.org/10.1016/j.semradonc.2017.08.009
31. Denkert C, Loibl S, Noske A, Roller M, Muller BM, Komor M, Budczies J, Darb-Esfahani S, Kronenwett R, Hanusch C, von Torne C, Weichert W, Engels K, Solbach C, Schrader I, Dietel M, von Minckwitz G (2010) Tumor-associated lymphocytes as an independent predictor of response to neoadjuvant chemotherapy in breast cancer. J Clin Oncol 28(1):105-113. https://doi. org/10.1200/JCO.2009.23.7370

32. Grabenbauer GG, Lahmer G, Distel L, Niedobitek G (2006) Tumor-infiltrating cytotoxic $\mathrm{T}$ cells but not regulatory $\mathrm{T}$ cells predict outcome in anal squamous cell carcinoma. Clin Cancer Res 12(11 Pt 1):3355-3360. https://doi.org/10.1158/1078-0432. CCR-05-2434

33. Kawai O, Ishii G, Kubota K, Murata Y, Naito Y, Mizuno T, Aokage K, Saijo N, Nishiwaki Y, Gemma A, Kudoh S, Ochiai A (2008) Predominant infiltration of macrophages and CD8(+) T Cells in cancer nests is a significant predictor of survival in stage IV nonsmall cell lung cancer. Cancer 113(6):1387-1395. https:// doi.org/10.1002/cncr.23712

34. Bhardwaj N (2007) Harnessing the immune system to treat cancer. J Clin Invest 117(5):1130-1136. https://doi.org/10.1172/JCI32136

35. Lesterhuis WJ, Haanen JB, Punt CJ (2011) Cancer immunotherapy—revisited. Nat Rev Drug Discov 10(8):591-600. https://doi. org/10.1038/nrd3500

36. Del CM-BP, Driver B, Morales-Rosado JA, Deavers M, Tacha D, Bernicker E, Cagle PT, Miller RA (2018) Correlation between programmed death receptor-1 expression in tumor-infiltrating lymphocytes and programmed death ligand-1 expression in nonsmall cell lung carcinoma. Arch Pathol Lab Med 142(11):13881393. https://doi.org/10.5858/arpa.2017-0516-OA

37. Kitano A, Ono M, Yoshida M, Noguchi E, Shimomura A, Shimoi T, Kodaira M, Yunokawa M, Yonemori K, Shimizu C, Kinoshita T, Fujiwara Y, Tsuda H, Tamura K (2017) Tumour-infiltrating lymphocytes are correlated with higher expression levels of PD-1 and PD-L1 in early breast cancer. ESMO Open 2(2):e000150. https://doi.org/10.1136/esmoopen-2016-000150

38. Mattox AK, Lee J, Westra WH, Pierce RH, Ghossein R, Faquin WC, Diefenbach TJ, Morris LG, Lin DT, Wirth LJ, LefrancTorres A, Ishida E, Chakravarty PD, Johnson L, Zeng YC, Chen H, Poznansky MC, Iyengar NM, Pai SI (2017) PD-1 expression in head and neck squamous cell carcinomas derives primarily from functionally anergic CD4(+) TILs in the presence of PD-L1(+) TAMs. Cancer Res 77(22):6365-6374. https://doi. org/10.1158/0008-5472.CAN-16-3453

39. Teng MW, Ngiow SF, Ribas A, Smyth MJ (2015) Classifying cancers based on T-cell infiltration and PD-L1. Cancer Res 75(11):2139-2145. https://doi.org/10.1158/0008-5472. CAN-15-0255

40. Mandal R, Senbabaoglu Y, Desrichard A, Havel JJ, Dalin MG, Riaz N, Lee KW, Ganly I, Hakimi AA, Chan TA, Morris LG (2016) The head and neck cancer immune landscape and its immunotherapeutic implications. JCI Insight 1(17):e89829. https ://doi.org/10.1172/jci.insight.89829

41. Khoury T, Nagrale V, Opyrchal M, Peng X, Wang D, Yao S (2018) Prognostic significance of stromal versus intratumoral infiltrating lymphocytes in different subtypes of breast cancer treated with cytotoxic neoadjuvant chemotherapy. Appl Immunohistochem Mol Morphol 26(8):523-532. https://doi.org/10.1097/PAI.00000 00000000466

42. Distel LV, Fickenscher R, Dietel K, Hung A, Iro H, Zenk J, Nkenke E, Buttner M, Niedobitek G, Grabenbauer GG (2009) Tumour infiltrating lymphocytes in squamous cell carcinoma of the oro- and hypopharynx: prognostic impact may depend on type of treatment and stage of disease. Oral Oncol 45(10):e167-174. https://doi.org/10.1016/j.oraloncology.2009.05.640

43. Hasmim M, Badoual C, Vielh P, Drusch F, Marty V, Laplanche A, de Oliveira DM, Roussel H, De Guillebon E, Oudard S, 
Hans S, Tartour E, Chouaib S (2013) Expression of EPHRINA1, SCINDERIN and MHC class I molecules in head and neck cancers and relationship with the prognostic value of intratumoral CD8+ T cells. BMC Cancer 13:592. https://doi. org/10.1186/1471-2407-13-592

44. Kim HR, Ha SJ, Hong MH, Heo SJ, Koh YW, Choi EC, Kim EK, Pyo KH, Jung I, Seo D, Choi J, Cho BC, Yoon SO (2016) PD-L1 expression on immune cells, but not on tumor cells, is a favorable prognostic factor for head and neck cancer patients. Sci Rep 6:36956. https://doi.org/10.1038/srep36956

45. Nguyen N, Bellile E, Thomas D, McHugh J, Rozek L, Virani S, Peterson L, Carey TE, Walline H, Moyer J, Spector M, Perim D, Prince M, McLean S, Bradford CR, Taylor JM, Wolf GT, Head NSPI (2016) Tumor infiltrating lymphocytes and survival in patients with head and neck squamous cell carcinoma. Head Neck 38(7):1074-1084. https://doi.org/10.1002/hed.24406

46. Park K, Cho KJ, Lee M, Yoon DH, Kim SB (2013) Importance of FOXP3 in prognosis and its relationship with p16 in tonsillar squamous cell carcinoma. Anticancer Res 33(12):5667-5673

47. Pretscher D, Distel LV, Grabenbauer GG, Wittlinger M, Buettner M, Niedobitek G (2009) Distribution of immune cells in head and neck cancer: CD8+ T-cells and CD20+ B-cells in metastatic lymph nodes are associated with favourable outcome in patients with oro- and hypopharyngeal carcinoma. BMC Cancer 9:292. https://doi.org/10.1186/1471-2407-9-292

48. van Kempen PM, Noorlag R, Swartz JE, Bovenschen N, Braunius WW, Vermeulen JF, Van Cann EM, Grolman W, Willems SM (2016) Oropharyngeal squamous cell carcinomas differentially express granzyme inhibitors. Cancer Immunol Immunother 65(5):575-585. https://doi.org/10.1007/s00262-016-1819-4

49. Wolf GT, Chepeha DB, Bellile E, Nguyen A, Thomas D, McHugh J, University of Michigan H, Neck SP (2015) Tumor infiltrating lymphocytes (TIL) and prognosis in oral cavity squamous carcinoma: a preliminary study. Oral Oncol 51(1):90-95. https://doi. org/10.1016/j.oraloncology.2014.09.006

50. Formenti SC, Demaria S (2013) Combining radiotherapy and cancer immunotherapy: a paradigm shift. J Natl Cancer Inst 105(4):256-265. https://doi.org/10.1093/jnci/djs629

51. Klug F, Prakash H, Huber PE, Seibel T, Bender N, Halama N, Pfirschke C, Voss RH, Timke C, Umansky L, Klapproth K, Schakel K, Garbi N, Jager D, Weitz J, Schmitz-Winnenthal H, Hammerling GJ, Beckhove P (2013) Low-dose irradiation programs macrophage differentiation to an iNOS(+)/M1 phenotype that orchestrates effective $\mathrm{T}$ cell immunotherapy. Cancer Cell 24(5):589-602. https://doi.org/10.1016/j.ccr.2013.09.014

52. Teng F, Mu D, Meng X, Kong L, Zhu H, Liu S, Zhang J, Yu J (2015) Tumor infiltrating lymphocytes (TILs) before and after neoadjuvant chemoradiotherapy and its clinical utility for rectal cancer. Am J Cancer Res 5(6):2064-2074

53. Homma Y, Taniguchi K, Murakami T, Nakagawa K, Nakazawa M, Matsuyama R, Mori R, Takeda K, Ueda M, Ichikawa Y, Tanaka K, Endo I (2014) Immunological impact of neoadjuvant chemoradiotherapy in patients with borderline resectable pancreatic ductal adenocarcinoma. Ann Surg Oncol 21(2):670-676. https ://doi.org/10.1245/s10434-013-3390-y

54. Lim YJ, Koh J, Kim S, Jeon SR, Chie EK, Kim K, Kang GH, Han SW, Kim TY, Jeong SY, Park KJ, Wu HG (2017) Chemoradiationinduced alteration of programmed death-ligand 1 and CD8(+) tumor-infiltrating lymphocytes identified patients with poor prognosis in rectal cancer: a matched comparison analysis. Int J Radiat Oncol Biol Phys 99(5):1216-1224. https://doi.org/10.1016/j.ijrob p.2017.07.004

55. Matsutani S, Shibutani M, Maeda K, Nagahara H, Fukuoka T, Nakao S, Hirakawa K, Ohira M (2018) Significance of tumorinfiltrating lymphocytes before and after neoadjuvant therapy for rectal cancer. Cancer Sci 109(4):966-979. https://doi.org/10.1111/ cas. 13542

56. Pelekanou V, Carvajal-Hausdorf DE, Altan M, Wasserman B, Carvajal-Hausdorf C, Wimberly H, Brown J, Lannin D, Pusztai L, Rimm DL (2017) Effect of neoadjuvant chemotherapy on tumorinfiltrating lymphocytes and PD-L1 expression in breast cancer and its clinical significance. Breast Cancer Res 19(1):91. https:// doi.org/10.1186/s13058-017-0884-8

57. Jung AC, Guihard S, Krugell S, Ledrappier S, Brochot A, Dalstein V, Job S, de Reynies A, Noel G, Wasylyk B, Clavel C, Abecassis J (2013) CD8-alpha T-cell infiltration in human papillomavirusrelated oropharyngeal carcinoma correlates with improved patient prognosis. Int J Cancer 132(2):E26-36. https://doi.org/10.1002/ ijc. 27776

58. Ward MJ, Thirdborough SM, Mellows T, Riley C, Harris S, Suchak K, Webb A, Hampton C, Patel NN, Randall CJ, Cox HJ, Jogai S, Primrose J, Piper K, Ottensmeier CH, King EV, Thomas GJ (2014) Tumour-infiltrating lymphocytes predict for outcome in HPV-positive oropharyngeal cancer. Br J Cancer 110(2):489-500. https://doi.org/10.1038/bjc.2013.639

59. Matlung SE, Wilhelmina van Kempen PM, Bovenschen N, van Baarle D, Willems SM (2016) Differences in T-cell infiltrates and survival between HPV + and HPV- oropharyngeal squamous cell carcinoma. Future Sci OA 2(1):FSO88. https://doi.org/10.4155/ fso. 15.88

60. Goethals L, Perneel C, Debucquoy A, De Schutter H, Borghys D, Ectors N, Geboes K, McBride WH, Haustermans KM (2006) A new approach to the validation of tissue microarrays. J Pathol 208(5):607-614. https://doi.org/10.1002/path.1934

61. van Diest PJ (2002) No consent should be needed for using leftover body material for scientific purposes. For BMJ 325(7365):648-651

Publisher's Note Springer Nature remains neutral with regard to jurisdictional claims in published maps and institutional affiliations. 